\title{
Baseline Risk and Preference for Reductions in Risk-to-Life
}

\author{
John K. Horowitz ${ }^{1,3}$ and Richard T. Carson ${ }^{2}$
}

Received October 19, 1992; revised January 28, 1993

\begin{abstract}
The typical model of individual attitudes toward risk-to-life suggests that an individual's willingness to pay for a reduction in mortality risk increases with the baseline risk. The higher-baseline hypothesis has been the subject of several empirical tests but results have so far been mixed. Using survey evidence, we present a situation in which subjects do prefer to reduce risks for which the baseline is higher. This finding is robust to several alternative explanations. Survey responses reflect subjects' concerns about government effectiveness in risk reduction, environmental effects associated with the various hazards, and other idiosyncratic elements of the risks; however, these concerns appear to occur in addition to, not in lieu of, the preference to reduce higher risks.
\end{abstract}

KEY WORDS: Baseline risk; consumer attitudes; rank-ordered logit.

\section{INTRODUCTION}

The typical model of individual attitudes toward risk-to-life ${ }^{(1)}$ suggests that an individual's willingness to pay for a reduction in mortality risk increases with the level of risk, the "baseline risk." (2) This higher-baseline hypothesis has been the subject of several recent empirical tests, but results have so far been mixed. Smith and Desvousges $^{(3)}$ reject the claim using survey data on willingness to pay for reductions in risk from hazardous wastes; however, other studies such as Viscusi and Evans $^{(4)}$ accept it (see Ref. 5 for a review). In the present paper, we test for the higher-baseline effect using data from two surveys of individual preferences for reduction of risks from sources such as pesticide residues on foods and leaks of hazardous wastes from Superfund sites. We find that people do prefer to reduce risks that are higher.

We also test a number of alternative explanations of the higher-baseline effect. One possible alternative

\footnotetext{
${ }^{1}$ Department of Agricultural and Resource Economics, University of Maryland, College Park, Maryland 20742.

2 Department of Economics, University of California, San Diego, La Jolla, California, 92093-0508.

${ }^{3}$ To whom all correspondence should be addressed.
}

explanation for our findings, unrelated to the Jones-Lee model, is that people want to reduce higher risks because they think that a larger reduction in risk can be obtained for a given expenditure on risk reduction; thus, they are interested in the amount of risk reduction rather than the baseline risk per se. A second alternative is that our subjects believe more people can be helped by risk-reduction efforts when risks are higher, so that the higherbaseline effect really results from altruistic preferences. Third, subjects may feel that greater environmental improvements will occur when higher-baseline health risks are reduced; the observed preference to reduce higherbaseline risks could then reflect concerns about the environment rather than about the size of the baseline risk. Although our findings suggest that the first and third of these effects are present, they do not appear to explain a large portion of the preference to reduce higher baseline risks. A marked preference for reducing higher baseline risks, ceteris paribus, appears to be a robust aspect of behavior in the context of our surveys.

In contrast to many of the previous papers that have looked at attitudes toward risk-to-life, we use respondents' subjective assessments of (relative) risk as our measure of baseline risk, rather than either statistics on 
past health outcomes (e.g., Bureau of Labor Statistics (BLS) data) or experimenter-provided information on risk, as in the Smith and Desvousges study. ${ }^{4}$ This allows us to avoid the problem either of using measures of baseline risk that are not the ones reflected in individual behavior, as may happen with BLS data, or of presenting in the survey information about the risk that conflicts with subjects' prior beliefs. ${ }^{(8)}$

\section{THE SURVEYS}

We report the results of two in-person surveys administered to members of two local Parents-Teachers Associations (PTA). ${ }^{5}$ These groups contain a range of ages, ethnic origins, income, and education levels. Using members of the PTA allows us to survey at low cost a relatively large number of subjects that is probably more representative of the U.S. population than other commonly surveyed groups, such as students or the League of Women Voters. Copies of the surveys are available from the authors.

Subjects were asked the following question (Survey I version):

A. Suppose the government were going to spend $\$ 50$ million per year to reduce risks caused by one of these substances. Rank-order the substances from your first choice (give a rank of 1) to your last choice (give a rank of 8) for applying this money to.

- Pesticide residues in drinking water

- Indoor formaldehyde

- Radon

- Automobile exhaust

- PCB in drinking water

- Pesticide residues on foods

- Increased radiation from the sun from use of CFCs

- Chlorine transported by train

Survey II was conducted 5 months later using similar questions, but three of the risky substances were changed. Pesticide residues in drinking water, indoor formaldehyde, and PCBs in drinking water were re-

${ }^{4}$ Other studies that use subjects' estimates of risk levels in their analysis are Gardner et al., (6) Gegax et al., (7) and Viscusi and Evans (4)

5 The surveys were administered at PTA meetings convened for another purpose. The PTA received $\$ 10$ for each completed survey but individual respondents were not paid. Prior to the meeting, members were told that a fund-raising opportunity would be available but neither the survey itself nor the subject area were announced. At the meeting, no one explicitly refused to fill out the survey, although it was possible for a potential respondent to refuse by turning in a blank survey (for which the PTA was still paid). A few PTA members who requested it were allowed to take the surveys home and return them later, but the number of people who did this was small. placed with foodborne organisms, leaking Superfund sites, and airborne mercury from incinerators. ${ }^{6}$ The working of the questions was similar for both surveys except for Environment (see below), where the scale was reversed.

An important problem in understanding preferences for risk regulation is that the subjects' beliefs about the risk levels are unknown. To treat this problem, respondents' subjective assessments of three different measures of the baseline risk were elicited through the following questions (Survey II versions):

Current Deaths: Rank-order the number of deaths caused by this substance in the U.S. last year. Give a rank of 1 to the substance that caused the most deaths and a rank of 8 to the substance that caused the fewest deaths.

- Radon

- Automobile exhaust

- Foodborne organisms

- Leaking Superfund sites

- Pesticide residues on foods

- Increased radiation from the sun from use of CFC's

- Shipping of chlorine

- Mercury from incinerators

Future Deaths: Rank-order the substances from 1 to 8 in terms of the number of deaths you think will likely be caused by the substance in the U.S. 20 years from now. (List of eight substances)

Personal Risk: Rank-order the substances from 1 to 8 in terms of how likely you think it is that the substance will cause a health problem for you personally, sometime in your life. (List of eight substances)

The ranking method used in these questions for measuring risk preferences and perceived risk levels has the advantage, missing in many of the other studies in this area, that it avoids the problem that arises when respondents who report high values of willingness to pay also report high levels of the risks. In that case, the higher-baseline phenomenon could be observed in the aggregate even if it did not occur for any individual subject.

The analysis also elicited subjects' perceptions about government effectiveness in reducing risks from the substance; the extend of exposure in the U.S.; and environmental effects. The survey questions were:

Government Effectiveness: Suppose that the government wanted to prevent deaths that were being caused by these substances. Rank-order the number of deaths that you think could be prevented, given the same amount of effort and expenditure by government on each substance. Give a rank of 1 to the substance that you think the government would be able to prevent the most deaths from and a rank of 8 to the substance we'd be

' See Ref. 5 for a discussion of the baseline hypothesis when there are multiple sources of risk. 
able to prevent the fewest deaths from. (List of eight substances)

- Radon

- Automobile exhaust

- Foodborne organisms

- Leaking Superfund sites

- Pesticide residues on foods

- Increased radiation from the sun from use of CFCs

- Shipping of chlorine

- Mercury from incinerators

Exposure: What percentage of the U.S. population do you think is probably exposed to this substance?

\begin{tabular}{|c|c|c|c|c|c|c|c|}
\hline \multirow[b]{2}{*}{ Randon } & \multicolumn{3}{|c|}{$\begin{array}{l}\text { Almost everyone } \\
\text { is exposed }\end{array}$} & \multicolumn{4}{|c|}{$\begin{array}{l}\text { Only a very few } \\
\text { people are exposed }\end{array}$} \\
\hline & $99 \%$ & $90 \%$ & $75 \%$ & $50 \%$ & $25 \%$ & $10 \%$ & \\
\hline Automobile exhaust & $99 \%$ & $90 \%$ & $75 \%$ & $50 \%$ & $25 \%$ & $10 \%$ & $1 \%$ \\
\hline Foodborne organisms & $99 \%$ & $90 \%$ & $75 \%$ & $50 \%$ & $25 \%$ & $10 \%$ & $1 \%$ \\
\hline Chemicals from leaking & & & & & & & \\
\hline $\begin{array}{l}\text { Superfund sites } \\
\text { Pesticide residues }\end{array}$ & $99 \%$ & $90 \%$ & $75 \%$ & $50 \%$ & $25 \%$ & $10 \%$ & $1 \%$ \\
\hline on foods & $99 \%$ & $90 \%$ & $75 \%$ & $50 \%$ & $25 \%$ & $10 \%$ & \\
\hline $\begin{array}{l}\text { Increased radiation } \\
\text { from sun }\end{array}$ & $99 \%$ & $90 \%$ & $75 \%$ & $50 \%$ & $25 \%$ & $10 \%$ & \\
\hline Shipping of chlorine & $99 \%$ & $90 \%$ & $75 \%$ & $50 \%$ & $25 \%$ & $10 \%$ & 14 \\
\hline $\begin{array}{r}\text { Aercury from } \\
\text { incinerators }\end{array}$ & $99 \%$ & $90 \%$ & $75 \%$ & $50 \%$ & $25 \%$ & $10 \%$ & \\
\hline
\end{tabular}

Environment: How serious are the effects of the current levels of use of this substance on plants and wildlife, not counting the possible effects on human health?

\begin{tabular}{lcccccccc} 
& \multicolumn{1}{c}{$\begin{array}{c}\text { Almost no } \\
\text { effects on } \\
\text { plants/wildlife }\end{array}$} & & \multicolumn{4}{c}{$\begin{array}{c}\text { Very serious } \\
\text { effects on } \\
\text { plants/wildlife }\end{array}$} \\
Pesticides & 1 & 2 & 3 & 4 & 5 & 6 & 7 \\
Radon & 1 & 2 & 3 & 4 & 5 & 6 & 7 \\
Foodborne organisms & 1 & 2 & 3 & 4 & 5 & 6 & 7 \\
Automobile exhaust & 1 & 2 & 3 & 4 & 5 & 6 & 7 \\
Leaking Superfund sites & 1 & 2 & 3 & 4 & 5 & 6 & 7 \\
Increased radiation from sun & 1 & 2 & 3 & 4 & 5 & 6 & 7 \\
Shipping of chlorine & 1 & 2 & 3 & 4 & 5 & 6 & 7 \\
Mercury from incinerators & 1 & 2 & 3 & 4 & 5 & 6 & 7
\end{tabular}

\section{RESULTS}

We analyzed the data using the rank-ordered logit procedure of Beggs et al. ${ }^{(9)}$ This procedure is based on a random utility model in which the utility from regulating a risk from a particular source depends on the risk's attributes. ${ }^{7}$ Maximum-likelihood results are given

\footnotetext{
7 This procedure assumes that utility from regulating source $i$ is independent of the set of sources to be ranked, the independence of irrelevant alternatives assumption. This assumption is strong, and its failure may explain differences between the two surveys (compare coefficients on radon in Table II).
}

in Tables I and II. For each of the eight substances (sources of risk), the dependent variable is the rank assigned by the subject to the substance in Question A, and the independent variables are the ranks or scales assigned for each of the six attributes. If $x_{1 i j}$ is the perceived baseline risk from hazard $i$ for subject $j$ (e.g., as measured by his ranking for the Current Deaths question) and if a ranking closer to one means higher risk, then the coefficient on $x_{1 i j} \beta_{1}$, measures the marginal utility of an increase in baseline risk. The baseline risk hypothesis is $\beta_{1}<0$.

A complete response is a set of rankings for all eight sources for all six attributes. There are 68 complete responses from Survey I and 104 complete responses from Survey II. For each survey, we ran four regressions. Two regressions included only the three "risk size" measures and dummy variables representing each substance, but no other risk attributes. The other two regressions included all six risk attributes and the dummy variables.

Coefficients are similar for the two surveys, and those that are significantly different from zero have the expected signs. The similarity between the estimates for the two surveys is particularly striking because they come from different subject groups who evaluated different sets of risky substances.

\subsection{Higher Baseline Risk}

The null hypothesis is that higher baseline risk (relatively more current or future deaths or greater personal

Table 1. Maximum-Likelihood Results ${ }^{a}$

\begin{tabular}{lcccc}
\hline & Survey I & Survey I & Survey II & Survey II \\
\hline Current deaths & -0.094 & -0.084 & -0.036 & -0.027 \\
& $(3.02)$ & $(2.60)$ & $(1.57)$ & $(1.10)$ \\
Future deaths & -0.189 & -0.153 & -0.259 & -0.238 \\
& $(6.15)$ & $(4.60)$ & $(10.24)$ & $(9.07)$ \\
Personal risk & -0.156 & -0.118 & -0.126 & -0.079 \\
& $(5.02)$ & $(3.56)$ & $(5.01)$ & $(2.75)$ \\
Government & & -0.043 & & -0.114 \\
effectiveness & & $(1.81)$ & & $(5.97)$ \\
Exposure & & 0.027 & & -0.027 \\
& & $(0.66)$ & & $(0.99)$ \\
Environment & & -0.211 & & 0.082 \\
& & $(5.13)$ & & $(4.48)$ \\
Log-likelihood & 606.94 & 593.41 & 945.59 & 924.57 \\
$N$ & 68 & 68 & 104 & 104 \\
\hline
\end{tabular}

absolute values of the ratio of the coefficient estimate to its standard error are in parentheses.

b The direction of the scale that Environment was measured on was different in Surveys I and II. 
Table II. Maximum-Likelihood Results with Hazard Dummy Variables Included ${ }^{\alpha}$

\begin{tabular}{|c|c|c|c|c|}
\hline & Survey I & Survey I & Survey II & Survey II \\
\hline Current deaths & $\begin{array}{l}-0.073 \\
(2.12)\end{array}$ & $\begin{array}{c}-0.069 \\
(1.98)\end{array}$ & $\begin{array}{c}-0.003 \\
(0.13)\end{array}$ & $\begin{array}{c}-0.003 \\
(0.13)\end{array}$ \\
\hline Future deaths & $\begin{array}{c}-0.172 \\
(5.02)\end{array}$ & $\begin{array}{c}-0.158 \\
(4.41)\end{array}$ & $\begin{array}{r}-0.245 \\
(9.00)\end{array}$ & $\begin{array}{c}-0.113 \\
(3.61)\end{array}$ \\
\hline Personal risk & $\begin{array}{l}-0.094 \\
(2.80)\end{array}$ & $\begin{array}{c}-0.080 \\
(2.25)\end{array}$ & $\begin{array}{c}-0.126 \\
(4.39)\end{array}$ & $\begin{array}{r}-0.237 \\
(8.41)\end{array}$ \\
\hline $\begin{array}{l}\text { Government } \\
\text { effectiveness }\end{array}$ & & $\begin{array}{c}-0.258 \\
(0.91)\end{array}$ & & $\begin{array}{c}-0.103 \\
(4.72)\end{array}$ \\
\hline Exposure & & $\begin{array}{c}0.053 \\
(1.18)\end{array}$ & & $\begin{array}{r}0.047 \\
(1.47)\end{array}$ \\
\hline Environment ${ }^{b}$ & & $\begin{array}{c}-0.132 \\
(2.93)\end{array}$ & & $\begin{array}{c}0.118 \\
(4.46)\end{array}$ \\
\hline $\begin{array}{l}\text { Radon } \\
\quad \text { (dummy variable) }\end{array}$ & $\begin{array}{c}0.96 \\
(5.03)\end{array}$ & $\begin{array}{c}1.08 \\
(5.08)\end{array}$ & $\begin{array}{r}-0.10 \\
(0.69)\end{array}$ & $\begin{array}{r}-0.22 \\
(1.22)\end{array}$ \\
\hline $\begin{array}{l}\text { Auto exhaust } \\
\text { (dummy variable) }\end{array}$ & $\begin{array}{l}1.65 \\
(9.08)\end{array}$ & $\begin{array}{c}1.67 \\
(8.55)\end{array}$ & $\begin{array}{c}0.92 \\
(6.38)\end{array}$ & $\begin{array}{c}0.84 \\
(4.44)\end{array}$ \\
\hline $\begin{array}{l}\text { Pesticides on foods } \\
\text { (dummy variable) }\end{array}$ & $\begin{array}{r}1.79 \\
(9.60)\end{array}$ & $\begin{array}{c}1.81 \\
(9.33)\end{array}$ & $\begin{array}{c}0.71 \\
(4.86)\end{array}$ & $\begin{array}{c}0.72 \\
(4.18)\end{array}$ \\
\hline $\begin{array}{l}\text { Solar radiation } \\
\quad \text { (dummy variable) }\end{array}$ & $\begin{array}{c}0.87 \\
(4.38)\end{array}$ & $\begin{array}{c}0.97 \\
(4.49)\end{array}$ & $\begin{array}{r}-0.03 \\
(0.22)\end{array}$ & $\begin{array}{c}0.26 \\
(1.39)\end{array}$ \\
\hline $\begin{array}{l}\text { Pesticides in } \\
\text { drinking water } \\
\text { (dummy variable) }\end{array}$ & $\begin{array}{c}2.04 \\
(11.05)\end{array}$ & $\begin{array}{c}2.05 \\
(10.63)\end{array}$ & & \\
\hline $\begin{array}{l}\text { Indoor formaldehyde } \\
\text { (dummy variable) }\end{array}$ & $\begin{array}{r}0.83 \\
(3.89)\end{array}$ & $\begin{array}{c}0.97 \\
(4.28)\end{array}$ & & \\
\hline $\begin{array}{l}\text { PCBs in drinking water } \\
\text { (dummy variable) }\end{array}$ & $\begin{array}{c}1.60 \\
(8.51)\end{array}$ & $\begin{array}{r}1.62 \\
(8.06)\end{array}$ & & \\
\hline $\begin{array}{l}\text { Leaking Superfund sites } \\
\text { (dummy variable) }\end{array}$ & & & $\begin{array}{c}0.69 \\
(4.28)\end{array}$ & $\begin{array}{c}0.82 \\
(4.68)\end{array}$ \\
\hline $\begin{array}{l}\text { Foodborne organisms } \\
\text { (dummy variable) }\end{array}$ & & & $\begin{array}{c}0.12 \\
(0.82)\end{array}$ & $\begin{array}{c}0.33 \\
(2.07)\end{array}$ \\
\hline $\begin{array}{l}\text { Mercury } \\
\quad \text { (dummy variable) }\end{array}$ & & & $\begin{array}{c}0.09 \\
(0.55)\end{array}$ & $\begin{array}{r}0.14 \\
(0.77)\end{array}$ \\
\hline Log-likelihood & 569.92 & 565.89 & 916.33 & 904.61 \\
\hline
\end{tabular}

a Absolute values of the ratio of the coefficient estimate to its standard error are in parentheses.

${ }^{b}$ The direction of the scale that Environment was measured on was different in Surveys I and II.

risk) is associated with stronger preference for risk reduction. All three variables have the correct signs in Tables I and II, and all except Current Deaths in Survey II are significantly different from zero at the $95 \%$ level. Thus, we accept the higher-baseline hypothsis. Future Deaths seems to have a larger effect on the rankings in Question A than Personal Risk, which in turn has a larger effect than Current Deaths, but all three attributes are highly correlated. ${ }^{8}$

\footnotetext{
${ }^{8}$ The correlations are: $\mathrm{PR}$ and $\mathrm{CD}, 0.62$ and 0.53 ; $\mathrm{PR}$ and $\mathrm{FD}, 0.62$ and $0.52 ; F D$ and $C D, 0.56$ and 0.52 (Surveys I and II).
}

It is possible that Current Deaths and Future Deaths do not directly measure the individual's perceived baseline risk, but they are likely to be closely associated with it. We expect that many subjects will feel personally at risk from the substances in about the same degree as the general population (which Current Deaths and Future Deaths measure), although such a presumption should indeed be tested. Note that by emphasizing mortality these attributes may also be capturing aspects of (personal) baseline risk beyond what are captured by Personal Risk. Future Deaths is probably a better indicator of either of these aspects of baseline risk than Current Deaths because of the long delay that occurs between exposure to most of these substances and the appearance of any adverse health effects; thus, a current high level of exposure will manifest itself as a cause of deaths occurring 20 years from now.

\subsection{Alternative Explanations}

A compelling alternative to the higher-baseline theory is that the amount of risk reduction that will occur as a result of regulation is believed to be bigger when the substance is responsible for more deaths. Thus, the higher-baseline effect could be observed if the subject were unconcerned with baseline risk itself and simply wanted the largest risk reduction (most lives saved) possible. This is a reasonable belief about the risk-reduction technologies available to the government. Government Effectiveness is positively correlated with Future Deaths in both surveys.

We use Government Effectiveness as a measure of the perceived size of the risk reduction that would be experienced. Government Effectiveness has a negative and significant coefficient in all cases, which implies that greater government effectiveness (ranked closer to 1) is associated with stronger preference for risk regulation, as expected. Thus, preferences for risk reduction reflect a desire for government action in those areas in which government is most effective.

Another explanation for the observed relationships between the ranking in Question A and the baseline risk is that preferences reflect an altruistic concern by the subjects about the number of people who will experience at least some reduction in risk, and that this number is positively correlated with the baseline risk. The hypothesis is that the subjects prefer to reduce risks from substances to which more people are exposed (i.e., that Exposure will have a negative coefficient in the utility 
from risk reduction)..$^{9}$ The estimated coefficients are not significantly different from zero in either case, and they are negative only for Survey II. Therefore, we reject this hypothesis.

Although the surveys emphasize the risks to human health, subjects may be equally concerned about environmental effects and the possibility for environmental improvement as a result of risk reduction. The variable Environment should have a negative coefficient in Survey I and a positive one in Survey II since the question is scaled in the opposite direction on the surveys. In both cases, the coefficients are highly significant and have the expected signs.

\subsection{Other Substance Attributes}

There may be other attributes that play a role in risk preferences. These include familiarity, voluntariness, dread, or newness (as Slovic et al. ${ }^{(10)}$ have suggested), salience, or other economic variables such as the cost of individual actions to reduce the risks. Some of these may be correlated with the perceived size of the risk.

To explore the possibilities, we added a dummy variable for each hazard to capture the effect of attributes not otherwise included. Results are shown in Table II. Although there are differences between the two surveys, subjects appear to prefer reducing the risks from auto exhaust, pesticides in water or on food, and water pollution, even when we account for the baseline risk, government effectiveness, or environmental effects. The significance of the coefficients on the dummy variables suggest that there may be other attributes, not included so far, that play a role in subjects' attitudes toward environmental health risks, as Slovic et al.'s results suggest. ${ }^{(10)}$ The small sample of hazards investigated makes it difficult to speculate what those attributes might be, and in future work we hope to consider this issue in more detail.

\subsection{Higher-Baseline Hypothesis vs. Alternative Explanations}

We estimated rank-ordered logit models (not shown) that excluded the three baseline risk measures and did likelihood ratio tests on the joint restriction that the coefficients on Current Deaths, Future Deaths, and Personal

\footnotetext{
${ }^{9}$ A substance's Exposure is coded as 1 if the response in the exposure question is $99 \%, 2$ if the response question is $90 \%$, and so on up to 7 if the response is $1 \%$.
}

Risk are zero. The hypothesis is rejected at the $95 \%$ level for each survey.

Further evidence comes from regressions with only the baseline risk measures included as explanatory variables. If Personal Risk and Future Deaths were merely "standing in" for other risk attributes, their coefficients should then change substantially when other variables are added to the regressions, even if these other variables are measured with error. Note, however, that large and essentially unchanged coefficients on Personal Risk and Future Deaths appear in all of the regressions, particularly for Survey II. Thus, it is unlikely that Future Deaths or Personal Risk are significant primarily because they capture concerns about government effectiveness, exposure, the environment, or unnamed idiosyncratic elements, rather than because subjects prefer to reduce higher baseline risks. The data consistently support the higherbaseline hypothesis.

\section{CONCLUDING REMARKS}

Our subjects appear to prefer to reduce risks for which the baseline risk is higher. This finding is robust to several alternative explanations. Survey responses also reflect subjects' concerns about government effectiveness in risk reduction, environmental effects associated with the various hazards, and other as-yet-unspecified elements of the risks; however, these concerns appear to occur in addition to, not in lieu of, the preference to reduce higher risks. Note that subjects' perceptions of baseline risks need not conform to more objective measures of the risks, and an evaluation of risk preferences based on such objective measures may not reveal a higherbaseline effect. Such risk perceptions may themselves be influenced by various economic and psychological features of the hazards.

The important implication of this finding for analysts interested in the economics of risk-to-life is that the "value of life" that is appropriate for valuing small risk changes is not necessarily the same for all risks, but instead is higher for higher risks. This puts a regulatory goal of equalizing the cost per life saved into question, since the work reported here implies that lives saved from reductions in higher baseline hazards are more valuable than lives saved from lower baseline hazards. It remains an open question, however, just how large this effect is and whether it can be used to rationalize existing differences in the implicit cost per life saved in society. 


\section{ACKNOWLEDGMENTS}

We thank Maureen Cropper, Bill Evans, John Quiggin, Ayal Kimhi, Ellen Post, and an anonymous reviewer for helpful comments. This research was funded in part by a cooperative agreement with the U.S. Environmental Protection Agency.

\section{REFERENCES}

1. M. W. Jones-Lee, "The Value of Changes in the Probability of Death or Injury," Joumal of Political Economy 82, 835-849 (1974).

2. M. C. Weinstein, D. S. Shepard, and J. S. Pliskin, "The Economic Value of Changing Mortality Probabilities: A DecisionTheoretic Approach," Quarterly Journal of Economics 94, 373$396(1980)$.

3. V. K. Smith and W. H. Desvousges, "An Empirical Analysis of the Economic Value of Risk Changes." Joumal of Political Economy 95, 89-114 (1987).
4. W. K. Viscusi and W. N. Evans, "Utility Functions That Depend on Health Status: Estimates and Economic Implications," American Economic Review 80, 353-374 (1990).

5. J. Horowitz, "The Analytics of Risk-to-Life." (unpublished manuscript, 1993).

6. G. T. Gardner, A. Tiemann, L. Gould, D. DeLuca, L. Doob, and J. Stolwijk, "Risk and Benefit Perceptions, Acceptability Judgements, and Self-Reported Actions Toward Nuclear Power," The Journal of Social Psychology 116, 179-197 (1982).

7. D. Gegax, S. Gerking, and W. Schulze, "Perceived Risk and the Marginal Value of Safety" (working paper prepared for the U.S. Environmental Protection Agency, 1985).

8. W. K. Viscusi, "Prospective Reference Theory: Toward an Explanation of the Paradoxes," Joumal of Risk and Uncertainty 2, 235-263 (1989).

9. S. Beggs, S. Cardell, and J. Hausman, "Assessing the Potential Demand for Electric Cars," Joumal of Econometrics 16, 1-19 (1981).

10. P. Slovic, B. Fischhoff, and S. Lichtenstein, "Characterizing Perceived Risk," Perilous Progress: Managing the Hazards of Technology (C. Hohenemser, R. Kates, and J. Kasperson, eds.) (London, Westview Press, 1985). 